Dr. William I. Richardson saw the case with me. Traction in his hands resulted as it had in mine. We advised the Casarean operation, which was consented to by the husband. 'The patient was removed from her house to the Lying-in Iospital, arriving there shortly after 6 o'clock. 'The abdomen and vagina were rendered aseptic by means of soap, permanganate of potash, peroxide of hydrogen and corrosive sublimate. Ether was given by Dr Starbird, and at 7.45 A. M. the patient was placed upon the operatingtable.

Drs. William L. Richardson, Charles M. Green and Abner Post were present. Drs. Holward Reynolds, Charles W. 'Townsend, John W. Bartol and Erb assisted, divided as follows: Dr. 'Townsend was to care for the baby, Dr. Reynolds was to control hemorrhage from the uterus, 1)r. Bartol was to assist me and I)r. Erb was to care for the sutures and sponges.

The first cut in the abdominal wall was made at $7.55 \frac{1}{2}$, the peritoneum was incised at 7.57 , the uterus was exposed at 7.58 , rubber ligatures placed around the uterus 7.59 , uterus incised $7.59 \frac{1}{4}$, child delivered $8.00 \frac{1}{2}$, cord tied and cut 8.01 , uterus sutured 8.02 to $8.18 \frac{1}{2}$, abdomen sutured 8.21 to 8.31 , dressing applied 8.34, patient in bed 8.40. 'Total time of operation $35 \frac{1}{2}$ minutes.

'The incision in the abdominal wall was in the median line, about seven inches in length and $\mathrm{ex}$ tended down to within three inches of the symphysis. 'The uterus was taken outside the abdominal cavity and covered with hot towels. The incision in the organ was made in the median line, beginning about two inches from the top of the fundus and extending downward for about five inches. The placenta was attached to the posterior surface of the uterus and was easily removed. The uterus was closed by seven deep silk sutures and by eight superticial ones which united the two peritoneal surfaces. As the uterus was outside there was no blood or detritus in the abdominal cavity. There was apparently no bleeding after the uterine sutures were tied. Ergotine was given subcutaneously, and firm contraction resulted. The abdominal wound was brought together and united by silkworm-gut sutures. 'The child was a girl, weighing seven pounds and one ounce. Hemorrhage was controlled by the hands of an assistant and the rubber ligiaturo was not tightened.

A fow weeks before delivery the patient had recovered from typhoid fever, and there had been more or less trouble with pain and swelling in both legs. 'This returned about two weeks after deliverv, and there was a certain amount of pain and tendernoss along the area of the large veins, extending as far as the popliteal space. 'This entirely passed away in the course of three weeks, and the convalescence after that was uninterrupted. 'Ihe mensurement of the pelvis is of interest. It was of the justo-minor type, and the measurements were: crests 9 inches, spines 8 inches, external conjugate 63 inches, and the intermal conjugate $4+$ inches. Deducting from this list measurement from one-half to threequarters of an inch, gives us a true conjugate of about three and one-half inches.

I believe that there are but two operations to be considered in connection with a polvis as small as this, when the child is living. 'They are symphysiotomy and Casarean soction. 'The first possibly would have been of avail. I believe not, however; and even if it could have been resorted to with advantage to the child, I should still prefer the section.

With the almost uniform success which attends the oneration when carried out after the manner of Sanger, I can only repeat what I have often said, that for me, at any rate, with the child and mother in good condition, craniotomy is an operation of the past never to be employed.

RESECTION OF 'THE IIEAD OF THE IIUMERUS FOR (OI,I) IRIEDUCIBIE DISIOCA'TION.'

$$
\text { Bу (1. н. MoNks, M.ь. }
$$

A man, fifty-nine years of age, was admitted to the liospital October 1st, with an old dislocation of the humerus. While wrestling, some ten months before, he stumbled and fell sidewise, striking upon the left arm and shoulder. A physician was called, who made the diagnosis of dislocation. The dislocation was reduced, but that night the head of the bone dropped out of the socket agrain. The next day it was again put back, but dropped out again soon after, and remained dislocated until the present time, the man hav-

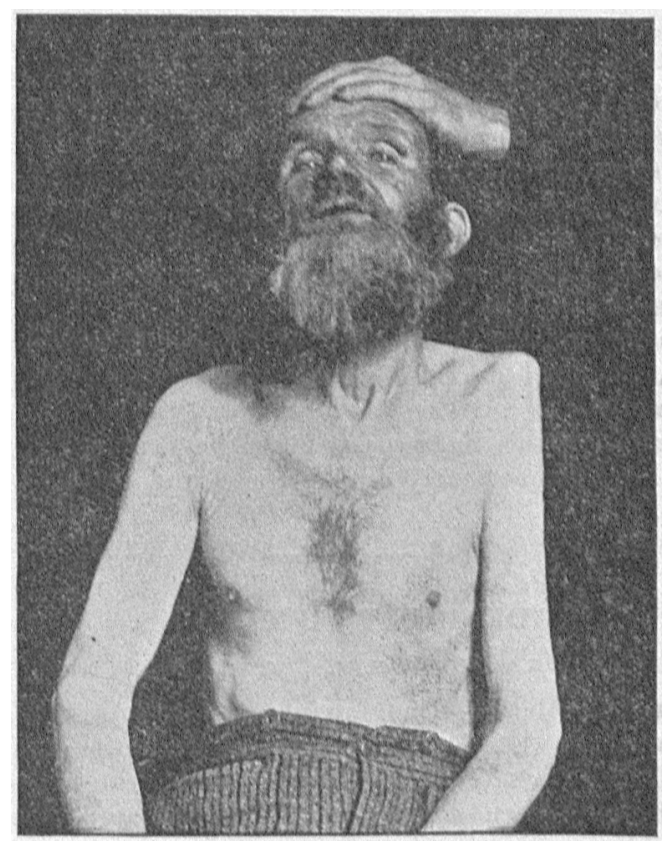

ing sought no medical assistance whatever. On admission to the hospital the dislocated shoulder was carefully examined, and found to be of the subcoracoid variety, with atrophy of all the muscles about the shoulder-joint, as well as of the muscles of the arm and hami. 'Tho patient's grasp was very weak, and voluntary movements extremely limited.

$\Lambda$ careful examination of the condition of the nerves was made by Dr. Prince, one of the neurologists of the hospital. Ilis report states that thero was complete uluar paralysis as well as partial paralysis of the median, musculo-spiral, and circumflex nerves. The man declared that he had been daily losing power in his arm up to the timo ho entered the hospital, when ho stated that it was about useless. The question

1 'l'his puper will appenr in the lBoston City Hospitnl Roports, 1 'Ihis peper
Sovonth surfes. 
arose as to whether operative interference should be attempted, and Dr. Cheever and I)r. Prince kindly acted as consultants in the matter. It was finally decided that, under the circumstances, excision of the head of the bone would relieve the pressure upon the nerves, and that possibly, to a certain extent, their functions might be restored. With the patient's consent, therefore, I excised the head of the humerus on October 17th, through an incision in the anterior margin of the deltoid. The muscles in this operation were the supraspinatus, teres minor, and subscapularis. The long tendon of the biceps was dislocated from its groove, but not divided. 'The wound healed rapidly by first intention, and the patient was very soon able to use his arm to a far greater degree and with a much greater range of motion than was possible before the oporation. He was very much pleased with the result of the operation. 'The condition of the nerves, also, improved considerably, but I am told by the neurologist that six months or a year will have to elapse after the operation before any very murked improvement can be noticel. Liven if no further improvement actually does take place in the condition of the nerves, I should feel satisfied with the result of the operation, in that the patient has thereby secured a much greater range of motion and a corresponding increase in the usefulness of his arm. It may be interesting to note that the head of the bone was very much atrophied, and that, on being removed, it could be easily crushed in the bone forceps, showing pretty conclusively that had an attempt been made to reduce the dislocation by manipulation, a fracture would probably have taken place at the neck of the bone, and thus a now complication would have been added, and no good whatever accomplished.

In view of the good result thus far obtained in this case, I thiuk I should be in favor of excising the head of the bone in any case of old-standing irreducible dislocation of the humerus, where the function of the arm has been seriously interfered with as in this case.

\section{ADENOID VEGETATIONS.}

J3Y FRANK M. BHLRMAN, M.D., WIEAT NICWTON, MABg.

Tue method of removing adenoid vegetations from the vault of the pharynx as practised in the clinic of Prof. B. Fraenkel in Berlin, appears to the writer so much better than any other that he has seen that he feels sure a description of it will be appreciated by those, not already familiar with it, who are interested in this subject.

'The chief feature of the method is to have the patient so lightly anesthetized that although conscious. ness is lost, reflex action is not abolished, and blood or mucus is therefore voluntarily expelled. The patient, if a child, is held in the arms of an assistant in the upright sitting position, the operator sitting in front of the patient. The anesthetic is administered to the primary stage of anesthesia; the mouth is opened, and the tongue depressed with a rather long and slender tongue depressor - no gag is used - and with the Gottstein curette tho growths are rapidly removed. Usually the larger portion of the separated growths is brought out with the instrument, and then tho patient, on account of the most decided irritation of the fauces, begins to expel the blood, mucus and portions of the growths which have been cut off. The finger is now passed into the naso-pharynx; if there still remain more vegetations, the curette is again used. It is often better to use the curette of IJartmann for the removal of these last remnants and tags of tissue. 'The operation done in this way - during the short duration of the primary anesthesia - must be done very quickly; the average time required is not far from one minute, although one fiequently does it in less time.

The obvious advantages of the method are its safety and the speed with which it can be done. After the necessary practice it can be done very thoroughly. 'The anesthetic used very antisfactorily in Fraenkel's clinic is bromide of ethyl. 'The writer has used ether in all his cases, and likes it better than the ethyl. Patients who are not excessively nervous, nor too young to control can be treated without general anesthesia. The benefit from the removal of these lymphoid masses from the naso-pharyux is so great, so quickly seen, and so permanent, that there are fow surgical procedures so satisfactory to the patient and the doctor. The opinion has been expressed, however, that notwithstanding the appreciation on the part of specialists and by very many general practitioners, of the exceedingly large number of children who suffer from the trouble, there still remain a great many cases which are not recognized and thus are debarred from the benefit of operative treatment. Mouth-breathing, earaches, " winter colds," nasal intonation, are symptoms that call for investigation, and simple palpation of the naso-pharynx will settle the question of the existence of adenoids.

\section{A CASE OF ABDOMINAL PREgNANCY.}

BY anorinc W. KAAN, M.l).,

Surgeon to Out-Patients, Free Iospital for Women, Boston.

'THIs case occurred in Brockton, Mass., in the practice of Dr. L. L. Frost, through whose kindness I was permitted to see it; and by his request I make this brief report.

The patient, a strong, well-nourished woman of thirty-six yeurs, had one child and a history of a miscarriage some eighteen months before the present pregnancy, followed by recurrent pelvic pain.

Dr. Frost wus called May J, 1895, the patient complaining of pain in the right groin. The last monstrual flow was about $A$ pril 1st, and this was considered one of her usual attacks. She apparently recovered from it, as she had from previous attacks.

One month later Dr. Frost was called for another attack of pain in the right side, much more severe than the previous one; but there was no collapse and nothing to indicato a ruptured tubal pregnancy, beyond a distinct tumor at the right side of the uterus, about the size of an orange, which could be felt from the outside. This gradually disappeared and the pationt recovered slowly. At about this time she began to have morning vomiting.

'There is nothing further to note until December 6, 1895, when Dr. Frost was called at noon and found the patient in labor. Examination of the abdomen showed a tumor of about full term with a sulcus across the lower third, and the part below the sulcus would harden as the pains came on. 'The fetal parts could be detected through the abdominal walls more distinctly 